\title{
Planetary Health Humanities-Responding to COVID Times
}

\author{
Bradley Lewis ${ }^{1}$ (iD
}

Accepted: 15 October 2020/ Published online: 28 October 2020

C) Springer Science+Business Media, LLC, part of Springer Nature 2020

\begin{abstract}
The coronavirus pandemic has shattered our world with increased morbidity, mortality, and personal/social sufferings. At the time of this writing, we are in a biomedical race for protective equipment, viral testing, and vaccine creation in an effort to respond to COVID threats. But what is the role of health humanities in these viral times? This article works though interdisciplinary connections between health humanities, the planetary health movement, and environmental humanities to conceptualize the emergence of "planetary health humanities." The goal of this affinity linkage is to re-story health humanities toward promotion of planetary health and community well-being. Wellbeing is critical because the main driver of environmental destruction and decreasing planetary health is coming from non-sustainable definitions of wellbeing. We need the arts and humanities to help reimagine the possibility of a sustainable community wellbeing. For health humanities, a basic role and narrative identity starts to emerge - we should become a planetary health (and well-being) humanities.
\end{abstract}

Keywords Health humanities · Corona-virus · Planetary health · Environmental humanities · Arts for health $\cdot$ Well-being $\cdot$ Sustainable development

Emerging infectious diseases (EIDs) are a significant burden on global economies and public health. Their emergence is thought to be driven largely by socio-economic, environmental and ecological factors... EID events are dominated by zoonoses (60.3\% of EIDs): the majority of these $(71.8 \%)$ originate in wildlife... and are increasing significantly over time.

Jones et al. 2008

Bradley Lewis

BL466@nyu.edu

1 Gallatin School of Individualized Study, New York University, 1 Washington Sq. \#609, New York, NY 10003, USA 
Nearly all of the most important human pathogens are either zoonotic or originated as zoonoses before adapting to human beings... Ecological changes have led to increased rates of emerging and re-emerging diseases.

Whitmee et al. 2015

\section{Introduction}

This article, written in the midst of the 2020 COVID-19 pandemic, considers some of meanings of coronavirus for health humanities. The two quotes above tell us that the virus is not a surprise. The medical literature knew as far back as 2008 that planet-wide socioeconomic, environmental, and ecological pressures were creating conditions for Emerging Infectious Diseases (EIDs) arising from novel zoonotic pathogens like COVID-19. As a result, by 2015 , there was already a mainstream academic and medical movement for a shift towards Planetary Health. The Lancet Commission on Planetary Health report explains the need for the movement: "by unsustainably exploiting nature's resources, human civilization... now risks substantial health effects from the degradation of nature's life support systems" (Whitmee et al. $2015,1973)$. The 2020 pandemic is the latest and so far most widespread example of these emerging health effects.

In this context, COVID-19 should be interpreted not as an isolated event or a crisis from nowhere. Rather, it should be read as a wake-up call toward more sustainable living. The implications of this interpretation cuts across both national and disciplinary boundaries. Each discipline, like each country and each region, must take seriously the meanings of COVID times. For health humanities, the basic direction of that meaning is clear-we should expand our focus toward promoting planetary health and well-being. We should become a planetary health humanities.

\section{Planetary health}

Developing planetary health humanities starts with working through the emerging discursive and narrative framings of a "planetary health" movement. The 2015 Rockefeller FoundationLancet Commission on Planetary Health $(\mathrm{CPH})$ is a good place to begin. The commission was composed of a diverse group of scientific contributors from medicine, ecology, biodiversity, and environmental health (Horton and Lo 2015). The Rockefeller Foundation, in its role and self-identity as a pioneer in the field of public health, initiated and funded the commission in collaboration with leading medical journal, the Lancet. The Foundation saw their efforts to create the field of "planetary health" as an extension of their public health work, or as Judith Rodin, then president of the Foundation called it: "public health-2.0" (2015, my italics). Their motivation was clearly stated: "The consensus in the scientific community is stark: our planet, and its ability to sustain human life, is in imminent danger." This danger, Rodin explains, comes from the consequences of one hundred years of pursuing progress through economic and development practices that have "created unintended consequences for our natural world." The result is changing patterns of known diseases and "increasing the likelihood that new unknown diseases will emerge" (2015).

The CPH articulates in detail how contemporary earth systems are deteriorating and how this deterioration is damaging human health and well-being - the bad news is that EIDs like 
COVID-19 are only one of a host of damaging consequences. In this situation of interlinking environmental and human health declines, the $\mathrm{CPH}$ provides a definition of planetary health:

the achievement of the highest attainable standard of health, wellbeing, and equity worldwide through judicious attention to the human systems - political, economic, and social - that shape the future of humanity and the Earth's natural systems that define the safe environmental limits within which humanity can flourish. Put simply, planetary health is the health of human civilization and the state of the natural systems on which it depends. (Whitmee et al. 2015, 1978)

This definition is contained in a box - "the concept of planetary health"-which elaborates key aspects of this definition. First, the CPH explicitly uses the WHO definition of health: "a state of complete physical, mental, and social wellbeing and not merely the absence of disease or infirmity" (1978). CPH, in defining Planetary Health, therefore joins with the WHO definition to give healthcare research, education, and practice the role of health promotion conceptualized as biopsychosocial (BPS) phenomena. The CPH underscores its BPS, or systems, focus by locating planetary health as part of an "ecological public health model" which includes "material, biological, social, and cultural" variables interacting in the complex and non-linear "dynamics of natural systems" (1978). Finally, the CPH "makes the case for widening the responsibility for health across disciplines and sectors beyond the traditional confines of the health sector" (1978). This last point is underscored by the CPH awareness that planetary health is an interdisciplinary all hands on deck priority which arises in this critical moment to "address the challenges of how best to protect and promote human health in the Anthropocene epoch" (1978).

Critically, the $\mathrm{CPH}$ also includes a section on the three main "drivers" of environmental and health deterioration: resource consumption, over-population, and technology (1983). Of the three drivers, resource consumption, coming primarily from "increasing absolute wealth," is "the main factor for increased absolute environmental impact" (1983, italics added). Increasing consumption from wealthy nations is creating a "profoundly unequal, resource intensive global economy" that is "unprecedented in human history" (1983). The implication is clear: " $a$ priority for research and innovation is to achieve accelerated progress in human development by use of much lower amounts of resources and energy from non-renewable sources than are used at present" (1983, italics added).

The CPH sees reason for hope in these seemingly intractable problems in the zeitgeist of the simultaneous emergence of the landmark UN Sustainable Development Goals. Adopted by all UN Member States in 2015 (the same year as the CPH), the 2030 Agenda for Sustainable Development creates a shared blueprint with the perspectives of $\mathrm{CPH}$ that combine human and planetary prosperity (United Nations 2015). As the UN explains:

At its heart are the 17 Sustainable Development Goals (SDGs), which are an urgent call for action by all countries - developed and developing - in a global partnership. They recognize that ending poverty and other deprivations must go hand-in-hand with strategies that improve health and education, reduce inequality, and spur economic growth - all while tackling climate change and working to preserve our oceans and forests. (United Nations 2020)

The SDGs have become the key framework for organizing the UN's international agenda on the social and environmental determinants of health and wellbeing. Like the concept of planetary health, the SDG's show the interdependence of health and well-being on factors much larger than the 
individual. The seventeen SDGs include poverty, hunger, education, inequality, sanitation, social justice, the environment, climate change, and responsible consumption.

The COVID-19 crisis provides stark evidence of CPH and UN SDGs interlinking of planetary health and wellbeing with human political, economic, and social systems. Not only has environmental damage created the conditions for novel zoonotic pathogens and EIDs, shortly after the pandemic we saw the consequences of the virus rapidly escalated by social determinants of disease (Braveman, Egerter and Williams 2011; Alegría et al. 2010). COVID19 outcomes are shaped by poverty, as physical environment (such as homelessness and smoke exposure), race, and gender all have considerable effect on morbidity and mortality from the disease. For example, in the US, the infection rate "is three times higher in predominantly black counties than in predominantly white counties, and the mortality rate is six times higher" (Abrams and Szefler 2020, 660). Part of the problem is that the capacity to physically distance is substantially more difficult in situations of adverse social determinants. School closures and job loss in low-income communities increase food insecurity, which increases malnutrition, which lowers immune response, which increases risk of infectious disease. As a result biomedical "unidisciplinary disease control strategies will never be truly sufficient to combat many infectious diseases, the underlying determinants of health also need to be addressed" (Butler-Jones, Wong 2016, 19).

The CPH agrees with this assessment and argues that planetary health works in concert with the UN SDGs to help focus and further conceptualize these goals. However, the very strength of SDGs, their comprehensiveness, also creates the risk that they will become fragmented and in need of integrating concepts. This is where CPH sees planetary health as particularly helpful: "The concept of planetary health can provide the necessary coherence for the overarching statement for the SDGs by integrating the aim of sustained improvements in human health and wellbeing with the preservation of key natural systems" (Whitmee et al. 2015, 2015). To do this, the CPH builds on the work of an interdisciplinary review committee composed of participants from the different SDGs devoted to identifying "conflicts and synergies" between the goals (Waage et al. 2015, 251). The review committee organized the SDGs in a figure which "shows how the proposed SDGs representing human wellbeing (inner circle) are dependent on those that provide the enabling infrastructure for development (the first ring) and the supporting natural systems (the outer ring)" (Whitmee et al. 2015, 2015, fig. 1).

This figure is particularly interesting in the double role it provides to "wellbeing." First, wellbeing is part a specific sustainability goal (SDG-3): to "ensure healthy lives and promote wellbeing" (2015). This highlights the relationship between wellbeing and the other SDGs and is consistent throughout CPH, WHO, and SDG's literature with the coupling of physical health with mental health (or wellbeing). In all of these literatures, any divide or hierarchical status between these two aspects of health (physical and mental) is erased. Second, wellbeing is placed in the center and therefore becomes the central target for all seventeen SDGs. As a result, wellbeing becomes the key organizing principle for future human development across all sectors. Going forward, this central role for wellbeing will become critical for understanding the possibilities of a planetary health humanities. But, before we can take that step, we need to think through the recent discursive and narrative meanings of "health humanities."

\section{Health humanities}

The term "health humanities," along with the related terms, "narrative medicine" and "critical medical humanities," have emerged in recent years out of conversations and debates in the 


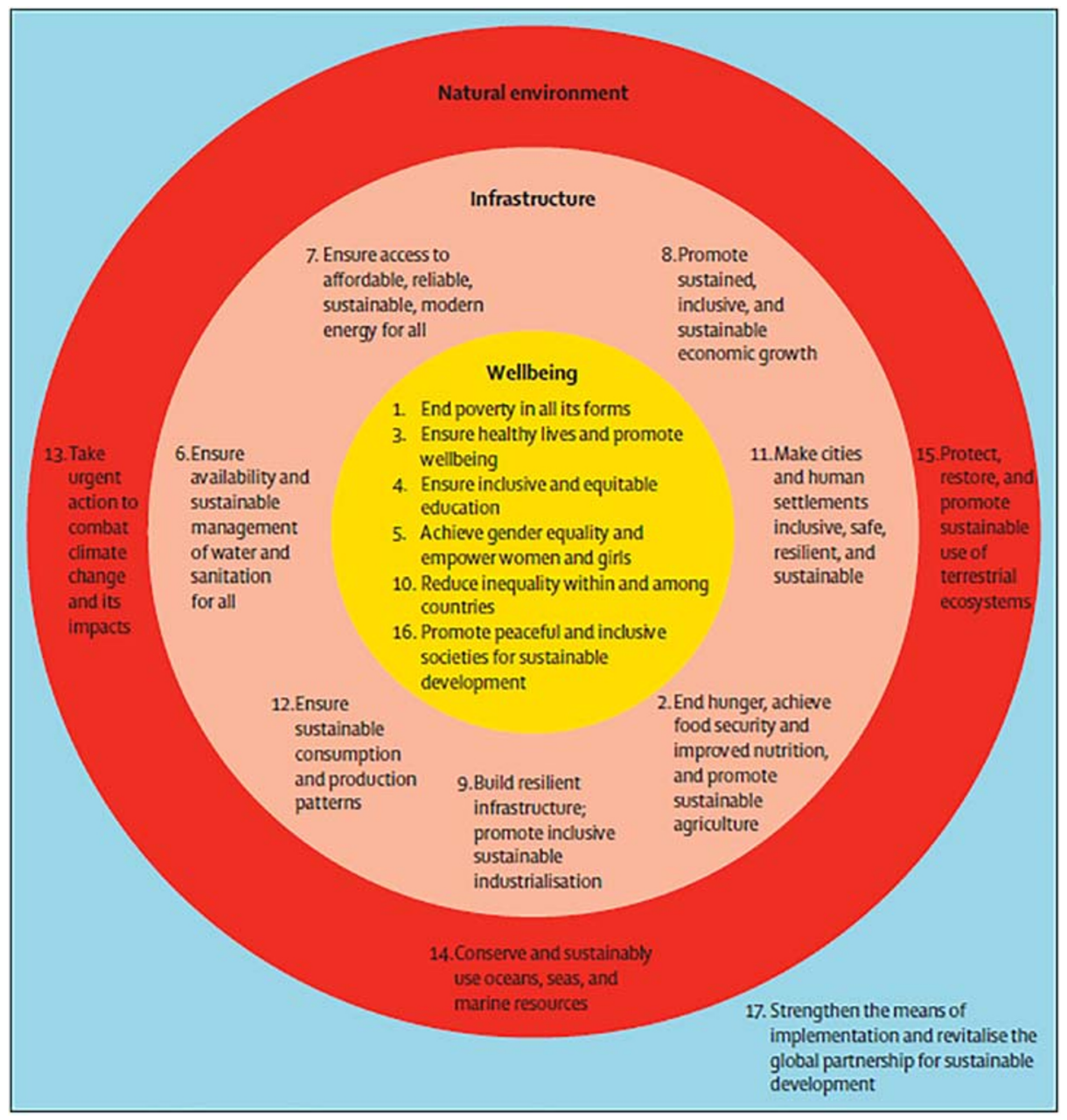

Fig. 1 Interactions of SDG (Whitmee et al. 2015, 2015)

interdisciplinary domain of "medical humanities." The four terms - medical humanities, critical medical humanities, narrative medicine, and health humanities - have been discussed extensively in the recent literature, and their meanings continue to evolve (Jones, Wear, and Friedman 2014; Charon et al. 2016; Atkinson, Macnaughton and Richards 2016; Bleakley 2020; Crawford, Brown, Charise 2020). In recent developments of these terms, health humanities, sees itself as an inclusive term that encompasses the other three terms, while at the same time extending the meaning and domain of the other terms to embrace additional interdisciplinary links - including expressive arts therapy and the arts for health movement (Crawford, Brown, and Charise 2020). Health humanities, from this perspective, has become the most expansive of the three terms, and, accordingly, it seems the most useful term for making planetary health connections. That said, it seems equally clear that "health humanities" is not the only vocabulary available in this domain and that the uses of "medical humanities," "critical medical humanities," and "narrative medicine" are all fluid enough that they can also be easily linked to planetary health and the UN SDGs. Indeed, in the context of 2020's 
cascading events of environmental destruction, COVID-19 health crisis, economic collapse, and racial and social civil conflict, it seems that they must do so.

Rather than focus on the different meanings of these humanities and healthcare domains, this section will concentrate on three points. First, all of these domains share a common conceptual ground with the BPS model and the systems theory that undergirds it. Second, of the different iterations of humanities and healthcare, health humanities most clearly expands beyond clinical training to include direct health promotion and activism. And, third, in its move beyond training and toward health promotion, health humanities most clearly includes mental health (or wellbeing) promotion as part of its work and self-understanding.

Starting with the links to the BPS model, all the humanities and healthcare domains have in common an understanding that the knowledge base basic to medicine, healthcare, and health includes more than biology. What is less understood is the links between arts and humanities approaches to healthcare and the BPS model's use of systems theory. Part of the reason for this is that these two approaches arose in parallel tracks. Meaningful resistance to biomedicine's exclusive preoccupation with biology began to emerge in the 1970's and 1980's. In key examples, George Engel argued for an expanded "biopsychosocial" systems approach to medicine which included not only the patients' bodies but also their psychic life and their social context (1977, 1980). Eric Cassell redefined the proper goals of medicine not as the battle against disease, but as the tending to the phenomenology of human suffering (1982). And Ian McWhinney urged medicine to adopt a phenomenology oriented "person-centered" approach which "should aim to understand the meaning of illness for the patient as well as provide a clinical diagnosis" $(1986,873)$. In addition, medical scholars began opening their knowledge base to inquiry coming from philosophy, literature, social science, political theory, gender studies, disability studies, and race studies. Several journals in these new interdisciplinary areas rapidly appeared: The Hastings Center Report (1975), Journal of Medical Ethics (1975), The Journal of Medicine and Philosophy (1976), Culture, Medicine, and Psychiatry (1976), Theoretical Medicine (1981), Literature and Medicine (1981), Social Science and Medicine (1983), Disability and Society (1986), Disability Studies Quarterly (1986), Journal of Medical Humanities (1989), Journal of Women's Health (1992), and Ethnicity and Health (1996).

In this collective move from reductive biomedical approaches to more expanded and interdisciplinary approaches, scholars and clinicians relied on differing logics and conceptual foundations. Philosophical and literary/narrative scholars most often relied on the inescapable and irreducible importance of agency - autonomy, experience, reflexivity, and meaning making. And social, cultural, and political scholars more often relied on equally inescapable and irreducible importance of structure - socio/economic, racial, gendered and disability relations and infrastructures which constrain and over determine human agency. Feminist scholars and activists in particular brought the two together with their rallying cry, "the personal is political." None of these sets of scholars and activists tended towards general systems theory, but instead they largely focused on agency or structure. By comparison, inclusive minded clinicians mixed concerns with personal agency and structural determinism together with a biopsychosocial systems model. As philosopher of medicine James Marcum puts it, humanizing practitioners differentiated themselves by blending phenomenological philosophy and systems theory: "the patient is recognized as a person occupying a lived context or a socioeconomic environment" (2008, 393).

These humanizing clinical efforts had limited (albeit important) effects on the healthcare system as a whole, and they tended to remain individualistic in their scope, but their prescient 
bringing together of agency, structure, and systems theory was on the right track. For example, in Re-Visioning Psychiatry: Cultural Phenomenology, Critical Neuroscience, and Global Mental Health, a recent major reconceptualization project for psychiatry, the editors argue that to understand mental health problems, we must understand that "biological, psychological, social, economic, and political circumstances all may contribute to vicious circles that cause and maintain symptoms, suffering, and disability" (Kirmayer, Lemelson, and Cummings 2015, xxi). Arthur Kleinman's preface explains that this requires health research, education and practice to engage in "the most deeply human context of clinical relationships and caregiving. Emotions, moral life, the local worlds that patients and families inhabit, and clinicians, too, and the economic and political forces that shape those worlds and institutions" (xix). Lawrence Kirmayer's puts this all together in a call for an "ecosocial view," which links dynamical systems theory with human agency: "we are self-describing beings who are partly governed by our own self-descriptions expressed in images, metaphors, narratives and scripts" (648). For Kirmayer, "complex systems theory points to the importance of understanding human behavior in terms of individual biography and social context - ways of knowing central to literature, the arts, and humanities" (648). The re-visioning efforts in psychiatry, the place where medicine most immediately feels the intersections of agency, structure, and systems, is a harbinger of future work in healthcare as a whole.

The second point about the humanities and healthcare domains is that of the different iterations discussed above, health humanities most clearly breaks out of clinical training and even the clinic itself to embrace health promotion and activism. As Paul Crawford put it in his introduction to the Routledge Companion to Health Humanities, "health humanities has moved beyond a predominating concern with training health professionals through the arts and humanities" $(2020,3)$. This move beyond training does not imply that health humanities has no role in clinical training, only that training concerns are not the limits of health humanities. In addition, health humanities does not privilege a "medical, biomedical or scientific frame or lens" for how we understand health, illness, and disease (3). Rather than being an add-on or a mere application of perspectives from the humanities on medicine and health care, health humanities embraces alternative and post-disciplinary possibilities for understanding illness and healing. This is where health humanities includes and links most directly to the arts, art therapy and the arts for health movement: "in the wider public culture [including but not limited to clinical training], the arts and humanities afford one of the greatest routes towards health, wellbeing, resilience and social connections" (401).

The many fields of arts and health promotion are diverse and have multiple iterations beyond health humanities, such as Arts for Health, Arts in Health, Arts-Health, Creative Health, and Arts into Health (Davies et al. 2016; Clift and Camic 2016; Fancourt 2017). In a recent overview, the U.S. National Organization for Arts in Health defines arts and health as "a maturing field dedicated to using the power of the arts to enhance health and well-being in diverse institutional and community contexts" (NOAH 2017, 5). Comprised of many subfields and affiliated fields, arts in health is similar to planetary health movement in that it supports the WHO definition of health as "a state of complete physical, mental and social well-being and not merely the absence of disease of infirmity" (5). This definition of health, first formulated in 1946, has come under scrutiny over the years but it's positively worded, multidimensional, and holistic framing has also stood the test of time and anticipates many of the holistic connections seen in the UN's recent SDGs. Most important for this discussion is how the definition links up with the goals of health promotion articulated by the 1986 Ottawa Charter for Health Promotion, which, like health humanities and arts for health, calls for an understanding of 
health promotion that is "not just the responsibility of the health sector" (Clift and Camic 2016, 5).

The third point is the easiest to make but worth emphasizing. Just as the above discussion reveals that the term "humanities" in health humanities is shorthand for "arts and humanities," the term "health" is also a shorthand for "health and wellbeing." The point is easy to make since "health" is paired with "wellbeing" in the first sentence of Health Humanities and Routledge Companion to Health Humanities and throughout these texts. In the latter example, the first sentence reads: "Health humanities is a fast-growing field of research, education, and practice that has generated a more inclusive, democratizing, and applied approach to arts and humanities in health care, health, and well-being" (Crawford et al. 2015; Crawford, Brown, Charise 2020,1). The significance of wellbeing for health humanities can also be seen in projects like "creative practice for mutual recovery," "the madness and literature network," and "the dementia arts and wellbeing network" showcased by the International Health Humanities Network (http://www.healthhumanities.org/). Health humanities inclusion of wellbeing is important to highlight since it links health humanities with $\mathrm{CPH}$, WHO, and SDG's emphasis on coupling physical health with mental health. And, as we will see in the next section, wellbeing is a key dimension of planetary health humanities.

\section{Planetary health humanities}

We are now almost ready to bring planetary health and health humanities together to form an affinity coalition. But before we can make that step a third partner is needed: environmental arts and humanities (which I will refer to as environmental humanities for short). Environmental humanities is a rapidly growing interdisciplinary field that combines humanities domains of eco-criticism, environmental philosophy, environmental history, feminist/queer/indigenous science and technology studies, and a range of environmentally engaged arts practices all in the service of environmental sustainability (Rose et al. 2012; Sorlin 2012; Emmett and Nye 2017; and Heise, Christensem, and Niemann 2017). The field recognizes that environmental science is not enough to understand environmental problems. In addition to science questions surrounding ecosystems, climates, populations, land use, pollution, and energy consumption, our sustainable futures are deeply entangled with questions of human meaning, ethics, life-style, justice, and politics. Environmental problems, from an environmental humanities perspective, are problems that involve both science and the arts and humanities since questions of nature can no longer be separated from questions of culture. To make progress in environmental sustainability, we must move beyond nature/culture divides to understand the many entanglements beyond this binary, including the way this binary has organized and fragmented human knowledge and academic disciplines.

In the context of COVID-19, these founding insights of environmental humanities have never been more prescient. COVID-19 is not just a biological science problem; it is also a human problem. And COVID-19 is not an isolated problem; it is deeply intertwined with human meaning, ethics, life-style, justice, and politics. Environmental humanities scholar Natalie Porter uses the term "risky zoographies" to signal how "ecological factors, interpersonal networks, and global market dynamics" combine to create novel and emergent zoonotic disease risks $(2012,103)$. These risky zoographies also reveal key insights beyond the nature/ culture binary. As Genese Marie Sodikoff explains 
Zoonosis unsettles the human subject because it entails an unwholesome intermingling of mammals, insects, and microscopic pathogens. The idea that persons are intrinsically and exclusively human is revealed to be factually incorrect, and therefore able to yield only partial insights into the rapidly changing conditions of life at present. Zoonosis emerges out of multispecies interactions inside individual bodies and out there in the external world. $(2017,113)$

These kinds of posthuman nature/culture theories become all too real in the context of pandemic revelations of what Sodikoff calls our "viral subjectivities." Recognizing our interspecies intermingling also creates a need to rework our self-understanding and the stories we tell about ourselves. Risky zoonotics are on the rise as the Anthropocene continues to cause climate warming and economic/ecological changes foster increased zoonotic conditions. But how will we tell the story of our viral subjectivities and how do we tell the story of the coronavirus global pandemic? This question reveals how COVID-19 is not simply a biomedical problem, it is very much a narrative problem. What is its past, its present, and its future?

By bringing together planetary health, health humanities, and environmental humanities, the creation of planetary health humanities takes seriously these concerns, recognizes and articulates the wisdom of a "wake-up call" narrative for our increasingly risky zoographies, and starts the process of reorganizing academic knowledge structures to respond to this wake up moment. If we compare the three fields that make up planetary health humanities, perhaps the first insight that emerges is their ecosystems common ground. Planetary health, health humanities, and environmental humanities are all directly linked with systems theory and therefore all connected to an ecological worldview. This similarity, however, is also a site of their differences, as they each interact with this ecological worldview in different ways. Planetary health and environmental humanities, unlike health humanities, expand their ecological thinking beyond the social political world to include the larger (and smaller) environmental and ecosystem connections. Health humanities and environmental humanities, unlike planetary health, are much more attentive to human agency, meaning making, and the role of arts, humanities, and cultures in shaping human life and human choices. Finally, planetary health and health humanities, unlike environmental humanities, are much more attentive to the role of wellbeing in human life choices and social systems and much more invested in direct promotion of human health and wellbeing. We need all three to put Humpty Dumpty together. We need a larger ecosystems view of human life which includes the role of posthuman meaning, agency, and political relations and which helps develop possible pathways to a sustainable wellbeing for posthumans.

The planetary health movement has been in the forefront of these three affinity domains in recognizing the critical importance of a sustainable wellbeing for our posthuman world. As we saw in fig. 1 above, the Lancet Commission on Planetary Health (CPH) considers wellbeing to be at the center of the many UN SDGs. This means that wellbeing can be seen as the organizing target for all of the other SDG's. Each SDG aims either toward wellbeing directly (as in SDG 3) or are key supports and scaffolds for human wellbeing (now understood to be posthuman wellbeing). The caretaking tasks of the SDG's are many and may seem overwhelming, but centering wellbeing means we do not do these tasks randomly, we do them for a reason. We need to take care of our natural environment-SDG's 13, 14, 15 (combat climate change, promote conservation and sustainability, and promote sustainable use of terrestrial ecosystems). We also need to take care of our infrastructure-SDG's 2, 6, 7, 8, 9, 11, 12 (end hunger, ensure water and sanitation, ensure energy access, promote sustainable growth, build 
resilient infrastructure, and make human cities and settlement inclusive and safe). Why do we need to do all of these things? Partly because all of these have their own intrinsic value, but also in a broader telos to promote posthuman wellbeing-SDG's 1, 3, 4, 5, 10, 16 (end poverty, ensure healthy lives, ensure education, achieve gender equality, reduce inequality, promote peaceful societies).

Although the CPH makes the argument that the SDG's are grounded in our common wellbeing, what is important to see is that they cannot justify the argument because, to do that, they need more than medical science. Organizing SDG's around a telos of wellbeing is a human meaning conclusion, and not one that medical science can make by itself. To understand and develop the argument - to locate it philosophically in its broadly Aristotelean frame and to make choices navigating this frame - we need the arts and humanities. And this is true not only for the overarching "target" conceptual underpinnings of $\mathrm{CPH}$, it is also true for the many controversial values contained in $\mathrm{CPH}$ - such as the need for growth or even the primacy of wellbeing over other values. There are extensive critiques and concerns of the potential ideological effects of growth, wellbeing, and sustainability as the target goals for life. We need the arts and humanities to help understand these conflicts and controversies. This is where both health humanities and environmental humanities can be invaluable for thinking through the very possibility of planetary health.

Health humanities work to directly promote health and wellbeing through the arts and humanities also becomes particularly valuable in this context. Admittedly, this is the newest aspect of health humanities, and it is the least developed dimension of this work. The other applied humanities we have looked at, such as medical humanities or environmental humanities, have not taken this promotion step and, for the most part, they stay with the goals of research, critique, and education. An important partial exception in environmental humanities is a recent collection titled, Sustainable Consumption and the Good Life, edited by Karen Lykke Syse and Martin Lee Mueller (2015). The collection opens with the basic question: "What does it mean to live a good life in a time when the planet is overheating, the human population continues to steadily reach new peaks, oceans are turning more acidic, and fertile soils the world over are eroding at unprecedented rates?" (1). And, not only that, what does it mean to live a good life in a time of worldwide injustice where " 1 billion people suffer from hunger or malnutrition," while increasing number of people "now enjoy unprecedented levels of wealth" with as many as five billion "middle-class" consumers expected by 2030 (1)? These basic questions open up to a meaning-making "convergence between sustainability issues, consumption practice and ideas of the good life" (1). Syse and Mueller choose the term "good life" over "wellbeing" or "happiness" because of its more overarching associations, but the key concerns are the same. We must begin to create meaning and life-style practices that bring together the "triple helix" of "sustainability, consumption, and the good life" (2). And, to be fair, this needs to be a quadruple helix of sustainability, consumption, justice, and the good life.

Syse and Mueller orient their hope for sustainable wellbeing in deep ecologist Arnee Naess' call for the creation and development of lives that are "simple in means, rich in ends" (2). Environmental historian David Shi's uses William Wordsworth's call for "plain living and high thinking" to reach a similar confluence $(1985,5)$. Both of these rallying cries start the process of understanding sustainable wellbeing and the good life, not in terms of austerity but in terms of experiential riches. Shi makes clear that cultural supports for unsustainable and high consumption life-styles wax and wane and that history provides a wealth of examples where people adopt life-style values and goals consistent with simple living, low consumption, and deep wellbeing. Wordsworth, like Naess, saw proximity to nature as part of the good life, 
but interestingly from the perspective of planetary health humanities, both Wordsworth and Naess also saw poetry and philosophy (respectively) as potentially key components of a sustainable wellbeing. This does not mean that arts and humanities are the only way to orient towards a good life that subordinates material desires for other kinds of experiential riches. It does not even mean that arts and humanities necessarily do this; it only means that they are a possible way of living a sustainable good life if organized in that direction.

And, if so, that means that the arts and humanities can not only help us understand environmental injustice, devastation, and resulting pandemic destructions, but they can also be a means of healing and reorienting. It is interesting in this light to compare the coronavirus pandemic with the playfully serious symbolism of what John de Graff, David Wann, and Thomas Naylor called the "all-consuming epidemic" of "affluenza" which has infected widespread notions of the good life and wellbeing (2005). Health humanities work directed toward the promotion of wellbeing through the arts and humanities can be seen in this light as work directed not only at alternative approaches to the good life but also as treatments for the epidemic of affluenza (what PHC calls the main driver of environmental destruction) and the pandemic sequalaes it has and will have caused. If the arts and humanities can be part of a richly rewarding experiential life of wellbeing that is lower on the consumption chain than a life of richly rewarding material consumption, then they become a critically important resource for the possibility of sustainable wellbeing and treating affluenza.

Certainly most people in the humanities as currently configured would not move in the direction of wellbeing. When English professor Helen Small looked at the current crisis in the humanities and the many ways that people justify arts and humanities, she found that the "claim that the humanities have a contribution to make to our individual and collective happiness" to be one of the least developed and least trusted arguments for the value of the humanities $(2014,6)$. Nonetheless, Small does articulate three key aspects of the happiness argument. The arts and humanities provide 1.) deeper understanding of happiness, 2.) enriched character development, and 3.) direct pleasure or hedonism. Starting with the first of these, the arts and humanities role in understanding happiness links to distinct role of the arts and humanities for interpretive understanding of the human condition more generally. If the humanities provide a human understanding that we cannot get from the sciences, one of the key places where that understanding can be brought to bear is on the question of human happiness.

The second argument for enriched character development is particularly tricky and risks sliding into polemics, but, at the same time, it is legitimate to see that different forms of training and study result in characteristically "trained habits of mind: distinctive intellectual priorities and tools to bear on distinctive kinds of object" (58). As philosopher Martha Nussbaum puts it, "the humanities offer insights" that are of inescapable "value as we seek to understand our lives." For example, they offer "a deeper understanding of love, death, anger, pain, and many other themes treated in great works of art, literature, and philosophy" (2010, xviii). There is no reason that they cannot also do so with regard to sustainable wellbeing.

The last of "arguments for happiness" for the arts and humanities is that they can bring happiness and wellbeing directly. Again, it is important to be careful here because arguments for the way arts and humanities can bring happiness and wellbeing can become inflated, but this does not take away that for many people the arts and humanities do provide a kind of pleasure and meaning for life that other activities do not. This deflationary argument keeps the value of the arts and humanities for those who enjoy them without falling into superiority 
complexes. And it is consistent with the wealth of work being done in the "arts for health" movement which is showing the many ways that arts and humanities can be directly valuable for health and wellbeing (Crawford, Brown and Charise 2020; Fancourt 2017; Tay, Pawelski and Keith 2018; Arts and Humanities Research Council 2018; Clift and Camic 2016).

Responding to COVID times, at its heart, means waking-up to the need to live differently at a fundamental level. Continued environmental devastation and injustice will bring continued risky zoographies, continued pandemics, and continued damages to human health through climate change, biodiversity loss, undernutrition, contaminated water use, and soil degradation (Whitmee et al. 2015). This makes it imperative that we reorganize our value systems towards more sustainable definitions of wellbeing and the good life. There are many ways this might be done, but orienting the arts and humanities towards this goal is an invaluable resource that should be mobilized in this direction. The arts and humanities provide distinctive approaches which help us understand environmental issues and questions of wellbeing in ways that other fields may not. They also have the potential to directly promote wellbeing through the creation of lifestyles that can be simple in means but rich in ends. The word "potential" in that last sentence is important. The arts and humanities do not necessarily create lifestyles that are simple in means; indeed they can be and often are consistent with elite material consumption. And, the arts and humanities do not necessarily create wellbeing; indeed many engaged in the arts and humanities are suffering in multiple ways. Plus, many in the arts and humanities are not even interested in, or would be deeply critical of, the very idea of sustainable wellbeing.

For all of these reasons, now is the time to do the affinity work and prefigurative work of bringing together those at the intersection of health humanities, environmental humanities, and the planetary health movement who are interested in working together toward sustainable lifestyles. The potential and the need are clear, the next step is to start organizing planetary health humanities programs which can help us move in the direction of an art of living consistent with sustainable wellbeing.

\section{Conclusion}

Perhaps the most obvious critique of developing planetary health programs is the way that they seem too small relative to the dangers and the needs. The last thing we need, a rational critic could conclude, is another interdisciplinary program. To create a new program is barely even rearranging the chairs on the Titanic; it is surely not redirecting the Titanic as it needs to be. What we need is global leadership, political change, and new legislation. Anything else is beside the point, or worse a dangerous distraction and diffusion of energies.

All of this is fair, but there does not have to be a sharp binary between cultural change and political change. They are both part of the tasks and demands on thinking. One of the things unfortunately clear is that, at a larger media cultural level, the global pandemic is not being read as a wake-up call towards more sustainable living. It is being read as a medical and public health crisis. That means that we are not yet at a major political transition moment. But, the tipping point will come if humans are to survive. In view of this, as Naomi Klein so helpfully put it in her still prescient, Shock Doctrine: The Rise of Disaster Capitalism, now is the time to learn from the playbook of conservative economists Milton Friedman (2007). Klein points out that Friedman clearly understands that "Only a crisis - actual or perceived - produces real change. When that crisis occurs, the actions that are taken depend on the ideas that are lying around" (166). Our opportunity at this current moment, while we work for larger political 
change, is to create the ideas and practices lying around for new ways of sustainable living and sustainable wellbeing when the wakeup call story finally emerges. Organizing those on campus that have an inclination towards using the arts and humanities to develop life-styles rich in meaning and reward but simple in means and consumption is an invaluable step in that direction.

\section{References}

Abrams, Elissa and Stanley Szefler. 2020. "COVID-19 and the Impact of Social Determinants of Health.” Lancet Respiratory Medicine 8:659-661.

Alegría, Margarita, Bernice Pescosolido, Sandra Williams, and Glorisa Canino. 2010. "Culture, Race/Ethnicity and Disparities: Fleshing out the Socio-cultural Framework for Health Services Disparities." In Handbook of the Sociology of Health, Illness, and Healing: A Blueprint for the 21st Century, edited by Bernice Pescosolido, Jane McLeod, Jack Martin, and A. Rogers, 336-382. New York: Springer.

Arts and Humanities Research Council. 2018. Exploring Mental Health and Wellbeing: The Role of Arts and Humanities Research. Great Britton: Arts and Humanities Research Council.

Atkinson, Sarah, Jane Macnaughton and Jennifer Richards, eds. 2016. The Edinburgh Companion to the Critical Medical Humanities. Edinburgh: Edinburgh University Press.

Bleakley, Alan, ed. 2020. Routledge Handbook of the Medical Humanities. New York: Routledge.

Braveman, Paula, Susan Egerter and David Williams. 2011. "The Social Determinants of Health: Coming of Age." Annual Review of Public Health 32:381-98.

Butler-Jones, D., and T. Wong. 2016. "Infectious Disease, Social Determinants and the Need for Intersectoral Action." Canada Communicable Disease Report 42: S1-18-S1-20. Accessed on 10 September 2020. https://doi.org/10.14745/ccdr.v42is1a04.

Cassel, Eric. 1982. "The Nature of Suffering and the Goals of Medicine.” New England Journal of Medicine 306 (11): 639-45.

Charon, Rita, Sayantani DasGupta, Nellie Hermann, Craig Irvine, Eric R. Marcus, Edgar Rivera Colsn, Danielle Spencer, and Maura Spiegel. 2016. Principles and Practices of Narrative Medicine. Oxford: Oxford University Press.

Clift, Stephen, and Paul Camic, eds. 2016. Oxford Textbook of Creative Arts, Health, and Wellbeing: International Perspectives on Practice, Policy, and Research. Oxford: Oxford University Press.

Crawford, Paul, Brian Brown, Charley Baker, Victoria Tischler and Brian Abrams, eds. 2015. Health Humanities. New York: Palgrave.

Crawford, Paul, Brian Brown, and Andrea Charise, eds. 2020. The Routledge Companion to Health Humanities. New York: Routledge.

Crawford, Paul and Brian Brown. 2020. "Health Humanities: A Democratizing Future beyond Medical Humanities." In Routledge Handbook of the Medical Humanities, edited by Alan Bleakley, 401-409. New York: Routledge.

de Graff, John, David Wann, and Thomas Naylor. 2005. Affluenza: The All-consuming Epidemic. 2nd edition. San Francisco, Berrett-Kohler Publishers, Inc.

Davies, Christina, Melanie Pescud, Julia Anwar-McHenry, and Peter Wright. 2016. "Arts, Public Health and the National Arts and Health Framework: A Lexicon for Health Professionals.” Australian and New Zealand Journal of Public Health 40 (4): 304-306.

Engel, George. 1977. "The Need for a new Medical Model: A Challenge for Biomedicine.” Science 196 (4286): $129-136$.

- 1980. "The Clinical Application of the Biopsychosocial Model." American Journal of Psychiatry 137 (5): 535-544.

Emmett, Robert and David Nye. 2017. The Environmental Humanities: A Critical Introduction. Cambridge: MIT Press.

Fancourt, Daisy. 2017. Arts in Health: Designing and Researching Interventions. Oxford: Oxford University Press.

Heise, Ersula, Jon Christensem, and Michelle Niemann, eds. 2017. The Routledge Companion to the Environmental Humanities. New York: Routledge.

Horton, Richard and Selina Lo, 2015. "Planetary Health: A new Science for Exceptional Action." Lancet 386: 1920-1922.

Jones, Kate, Nikitta Patel, Marc Levy, Adam Storeygard, Deborah Balk, John Gittleman, and Peter Daszak. 2008. "Global Trends in Emerging Infectious Diseases." Nature 451: 990- 93. 
Jones, Therese, Delease Wear, and Les Friedman. 2014. Health Humanities Reader. Rutgers: Rutgers University Press.

Kirmayer, Laurence, Robert Lemelson, and Constance Cummings. 2015. Re-visioning Psychiatry: Cultural Phenomenology, Critical Neuroscience, and Global Mental Health. New York, NY: Cambridge University Press.

Klein, Naomi. 2007. Shock Doctrine: The Rise of Disaster Capitalism. New York: Metropolitan Books/Henry Holt.

Marcum, James. 2008. "Reflections on Humanizing Biomedicine.” Perspectives in Biology and Medicine 51 (3): $392-405$.

McWhinney, Ian. 1986. "Are We on the Brink of a Major Transformation in Clinical Method?" Canadian Medical Association Journal 35:873-878.

National Organization for Arts in Health. 2017. Arts, Health, and Wellbeing in America. San Diego, CA: Author.

Nussbaum, Martha. 2010. Not for Profit: Why Democracy Needs the Humanities. Princeton: Princeton University Press.

Porter, Natalie. 2012. "Risky Zoographies: The Limits of Place in Avian Flu Management." Environmental Humanities 1:103-121.

Rodin, Judith. 2015. "Planetary Health: A new Discipline in Global Health." The Rockefeller Foundation. https://www.rockefellerfoundation.org/blog/planetary-health-a-new-discipline-in-global-health/.

Rose, Deborah, Thom van Doorenb, Matthew Chrulewb, Stuart Cookec, Matthew Kearnesb and Emily O'Gorman. 2012. "Thinking through the Environment, Unsettling the Humanities." Environmental Humanities 1:1-5.

Shi, David. 1985. Simple Life: Plain Living and High Thinking in American Culture. Oxford: Oxford University Press.

Small, Helen. 2014. Value of the Humanities, Oxford: Oxford University Press.

Sodikoff, Genese. 2017. "Multispecies Epidemiology and the Viral Subject." In The Routledge Companion to the Environmental Humanities, edited by Ersula Heise, Jon Christensem, and Michelle Niemann, 112-120. New York: Routledge.

Sörlin, Sverker. 2012. "Environmental Humanities: Why should Biologists Interested in the Environment take the Humanities Seriously?" BioScience 62 (9): 788-789.

Syse, Karen and Martin Mueller, eds. 2015. Sustainable Consumption and the Good Life. New York: Routledge.

Tay, Louis, James Pawelski, and Melissa Keith. 2018. "The Role of the Arts and Humanities in Human Flourishing: A Conceptual Model.” The Journal of Positive Psychology 13 (3): 215-225.

United Nations. 2015. Transforming our World: The 2030 Agenda for Sustainable Development. New York: United Nations Secretariat.

United Nations. 2020. "The 17 Goals." United Nations Department of Economic and Social Affairs. https://sustainabledevelopment.un.org/sdgs.

Waage, Jeff, Christopher Yap, Sarah Bell, Caren Levy, Georgina Mace, Tom Pegram, Elaine Unterhalter, Niheer Dasandi, David Hudson, Richard Kock, Susannah Mayhew, Colin Marx, Nigel Poole. 2015. "Governing the UN Sustainable Development Goals: Interactions, Infrastructures, and Institutions.” Lancet 3:251-252.

Whitmee, Sarah, Andy Haines, Chris Beyrer, et al. 2015. "Safeguarding Human Health in the Anthropocene Epoch: Report of the Rockefeller Foundation-Lancet Commission on Planetary Health." Lancet 386 (10007): 1973-2028.

Publisher's Note Springer Nature remains neutral with regard to jurisdictional claims in published maps and institutional affiliations. 